\title{
Ocular Cyłotoxicity Evaluation of Medical Devices such as Contact Lens Solutions and Benefits of a Rinse Step in Cleaning Procedure
}

\author{
Mélody Dutot ${ }^{1 \S}$, Jacques Vincent ${ }^{2 \S}$, Nicolas Martin-Brisac ${ }^{1}$, Isabelle Fabre ${ }^{2}$, \\ Christine Grasmick ${ }^{2}$, and Patrice Rat ${ }^{1}$ \\ ${ }^{1}$ Chimie-Toxicologie Analytique et Cellulaire (EA 4463), Université Paris Descartes, Sorbonne Paris Cité, Faculté de Pharmacie, \\ Paris, France; ${ }^{2}$ Agence nationale de sécurité du médicament et des produits de santé (ANSM), Direction des Contrôles, \\ Vendargues, France
}

\begin{abstract}
Summary
Contact lens care solutions are known to have toxic effects on the ocular surface. The ISO 10993-5 standard describes test methods to assess the cytotoxicity of medical devices, but it needs some improvements to discriminate contact lens care multipurpose solutions. First we evaluated the biological hazards associated with the use of ophthalmic solutions, running a collaborative study with the French medical agency to propose adapted tools to study contact lens care solutions' ocular cytotoxicity (human cell line, short incubation times, and no dilution of solutions to test). Then we took into account the potential risk of these ophthalmic solutions adsorbed on contact lenses and released on the ocular surface, highlighting the addition of a rinse step with unpreserved marine solution in the contact lens cleaning procedure to avoid side effects of contact lens care solutions.
\end{abstract}

Keywords: cytotoxicity, standardization, microplate, medical device, Draize alternative

\section{Introduction}

Many contact lens wearers experience various ocular problems, and they use a wide array of multipurpose solutions for contact lens disinfection. These solutions have to perform disinfection and rinse the contact lens without inducing tolerance problems. Although topically administered ocular solutions are used with apparent safety and good tolerance, there is growing evidence that long-term use of these products damages conjunctival and corneal epithelial cells. So, over the years, contact lens wear has been associated with numerous adverse ocular reactions (Chang et al., 1999; Ladage et al., 2001). Of these, microbial keratitis is the most devastating, as it can lead to permanent vision loss (Bourcier et al., 2003).

Multipurpose disinfecting contact lens solutions, which are medical devices (class $2 b$ ), consist of a single solution for disinfecting, rinsing, and storing the lenses. Like many medical preparations, these solutions contain preservatives known to cause severe side effects to the ocular surface. Preservatives are absolutely necessary in multipurpose solutions, as they are the active ingredients of these solutions. Benzalkonium chloride (BAC), a quaternary ammonium, is the preservative currently used the most in ophthalmology. Adverse effects of BAC are important because BAC turnover is very slow, and quaternary ammonium molecules can remain in ocular tissue from 48 hours up to 7 days after a simple drop administration (Champeau and Edellhauser, 1998; Green et al., 1987). BAC has been known for decades to be toxic (Burstein 1980, 1985; De Saint Jean et al., 1999). Many in vivo and in vitro studies have shown its toxicity on conjunctival and corneal cells (Debbasch et al., 2001; Grant et al., 1996; Green et al., 1987; Saarinen-Savolainen et al., 1998; Takahashi, 1982; Tripathi et al., 1992), in particular its necrotic and apoptotic effects (Debbasch et al., 2000; Geerling et al., 2001). BAC has been demonstrated to be responsible for reactive oxygen species overproduction and high $\mathrm{P} 2 \mathrm{X} 7$ receptor activation, which could explain fluoroquinolone eye drop intolerance (Dutot et al., 2006). Finally, new markers have been developed to detect early toxic damage from BAC treatment (Pauly et al., 2009). For all these reasons, BAC qualifies as a positive control for cytotoxicity studies (Mowrey-McKee et al., 2002).

In recent years, new quaternary ammoniums have been developed, such as polidronium chloride $\left(\operatorname{Polyquad}^{\circledR}\right)$, which is 
present in some contact lens solutions. Other preservatives, such as PHMB (polyhexamethylenebiguanide), polymers of biguanide, are frequently used in contact lens solutions. Unlike for quaternary ammonium, the ocular toxicity induced by these preservatives is relatively unknown.

For many years, numerous lens care solutions have been tested according to different in vivo and in vitro experimental protocols. Results demonstrated that these products may cause more or less important adverse effects depending on the formula of the product (Begley et al., 1994; Dutot et al., 2008a; Lebow and Schachet, 2003; Li et al., 2003; Mowrey-McKee et al., 2002; Santodomingo-Rubido et al., 2006; Tchao et al., 2002; Wright and Mowrey-McKee, 2005). Furthermore, repeated applications of preserved eye drops may lead to cumulative damage.

Evaluation of in vitro toxicity of lens care solutions is required because of its potential predictive value for ocular irritation in humans. ISO 10993-5 standard (International Organisation for Standardization), is the medical device biocompatibility assessment standard that evaluates cytotoxicity induced by medical devices such as contact lens solutions. It is a good basis for evaluating the tolerance of these products, but experimental procedures provided in this standard are not adapted to ocular solutions. It is necessary to add some minor corrections to fit the current use of contact lens care solutions. The cells used in ISO 10993-5 standard protocols are mammalian cells but not human cells, the contact duration is often very long, from 24 hours to 6 days, and the product being tested for cytotoxicity is diluted. The real use of contact lens care solutions is different, since neat solutions are in direct contact with human cells during a short contact time. Consequently, some solutions available on the market have passed ISO 10993-5 standard but still can be potentially toxic for the ocular surface. Therefore, an alternative care regimen is needed to prevent toxic contact lens solutions from reaching the ocular surface.

The first aim of this study is to set up experimental procedures adapted to the use of contact lens care solutions: neat solution, short incubation time, cells of human origin. This experimental protocol must be sensitive, simple, and fast; it also must give reproducible results. In terms of screening this method also has to give information quickly and avoid important variability in the data that occurs with in vivo studies such as the Draize test on rabbits (Claydon and Efron, 1994; Gower et al., 1994). Interlaboratory assays were performed to estimate the reproducibility of the data and to choose the protocol that is best adapted to discriminate among products. Experimental procedures were set up using BAC as positive control, and six marketed soft contact lens care solutions were tested in two French research centers' laboratories.

The second aim is to evaluate the efficacy of a contact lens rinse with unpreserved saline solutions to limit the side effects of contact lens solutions.

These new methods should be integrated within the standardization framework to be useful for manufacturers who want to implement and develop new multipurpose contact lens solutions.

\section{Materials and methods}

\section{Cell culture}

Wong-Kilbourne-derived human conjunctival epithelial cells (established cell line Wong-Kilbourne derivative of Chang conjunctiva, clone 1-5c-4, American Type Culture Collection: ATCC-CCL-20.2) and human corneal epithelial cells (HCE cell line, Riken Cell Bank RCB1384) were cultured under standard conditions $\left(5 \% \mathrm{CO}_{2}, 95 \%\right.$ humidified air, $\left.37^{\circ} \mathrm{C}\right)$ in Dulbecco's minimum essential medium for WKD cells and in DMEM:HAM F12 (50:50) for HCE cells (Gibco, Villebon sur Yvette, France). Medium was supplemented with Glutamax or glutamine and with $10 \%$ fetal bovine serum (Gibco). Cells from passages 15 through 30 (after ATCC initial passage 65) were used in all experiments. Normal culture development was assessed daily by phase-contrast microscopy.

Confluent cultures were removed by trypsin incubation and cells were counted. They were then seeded into 96-well culture microplates (Corning, Schiphol, The Netherlands) at 18,000 cells per well $(90,000$ cells $/ \mathrm{ml} ; 200 \mu 1 /$ well $)$. Cultures were kept at $37^{\circ} \mathrm{C}$ for $24 \mathrm{~h}$ prior to any exposure to test solution to let the cells attach to the bottom of the microplate and reach sub-confluence.

\section{Experimental procedures to adapt ISO 10993-5 standard} to ocular cytotoxicity potential assessment: application to contact lens care solutions

This study was conducted in two laboratories. For all incubations, three independent assays were performed.

Incubations: When conjunctival cells reached approximately $80 \%$ confluence, culture medium was removed and the cells were exposed to four concentrations $(0.0005 \%$; $0.001 \%$; $0.003 \%$; and $0.005 \%$ ) of benzalkonium chloride (BAC, SigmaAldrich, Saint-Quentin Fallavier, France; CAS 63449-41-2, B6295, Batch036K0208). These solutions were prepared in phosphate buffered saline (PBS, Gibco).

Six marketed contact lens multipurpose solutions were tested: one quaternary ammonium solution, Opti-free Express ${ }^{\circledR}$ (Alcon, Fort Worth, USA) containing Polyquad ${ }^{\circledR}$ (polidronium chloride) $0.001 \%$ and Aldox ${ }^{\circledR}$ (myristamidopropyldimethylamine) $0.0005 \%$, four PHMB solutions, Boston Simplus ${ }^{\circledR}$ (Bausch\&Lomb, Kingston, UK), L'éphémère (Ciba Vision, Duluth, USA), Menicare (Menicon Pharma, France), Renu MPS ${ }^{\circledR}$ (Bausch\&Lomb, Kingston, UK), and one Oxychlorite ${ }^{\mathrm{TM}}$ system, Regard (Horus Pharma, France). Each bottle was divided into two equal volumes in sterile bottles and each lab received a bottle. The six products (see formulations in Tab. 1) were tested neat, and three different incubation times were studied: 15, 30, and $60 \mathrm{~min}$. Culture medium was used as negative control.

\section{Cell viability: membrane integrity using the neutral} red fluorometric assay

Membrane integrity, correlated with cell viability, was evaluated using the neutral red dye (NR; Fluka, Buchs, Switzerland) following incubation with the different products. After removal of the products being tested, $200 \mu 1$ per well of neutral red 
Tab. 1: Chemical composition of multipurpose solutions at the time of the study

\begin{tabular}{|c|c|c|c|c|c|c|}
\hline & \begin{tabular}{|c|} 
A \\
(Renu, \\
Bausch \& Lomb)
\end{tabular} & $\begin{array}{c}\text { B } \\
\text { (Menicare, } \\
\text { Menicon) }\end{array}$ & $\begin{array}{c}\text { C } \\
\text { (Regard, } \\
\text { Horus Pharma) }\end{array}$ & $\begin{array}{c}\text { D } \\
\text { (Ephemere, } \\
\text { Ciba Vision) }\end{array}$ & $\begin{array}{c}E \\
\text { (Optifree, } \\
\text { Alcon) }\end{array}$ & $\begin{array}{c}\text { F } \\
\text { (Boston, } \\
\text { Bausch \& Lomb) }\end{array}$ \\
\hline $\begin{array}{l}\text { Poloxamine/Tetronic } \\
1304\end{array}$ & $1 \%$ & & & & $\mathrm{UC}^{1}$ & \\
\hline PHMB & $0.00005 \%$ & $0.0001 \%$ & & $0.0001 \%$ & & $0.0001 \%$ \\
\hline $\begin{array}{l}\text { Pluronic/Poloxamer } \\
407\end{array}$ & & & UC & UC & & \\
\hline Polyquad $^{\circledR}$ & & & & & $0.001 \%$ & \\
\hline Aldox $^{\circledR}$ & & & & & $0.0005 \%$ & \\
\hline Oxychlorite & & & UC & & UC & \\
\hline $\begin{array}{l}\text { Chlorhexidine } \\
\text { gluconate }\end{array}$ & & & & & & $0.003 \%$ \\
\hline
\end{tabular}

1UC: unknown concentration

solution at $0.05 \mathrm{~g} / \mathrm{l}$ were added to living cells, and the microplate was incubated for $3 \mathrm{~h}$ at $37^{\circ} \mathrm{C}$ in a moist atmosphere with $5 \% \mathrm{CO}_{2}$. The cells then were washed with PBS, and the dye was extracted from the viable cells with a solution of acetic acid-ethanol. The plate was agitated on a microplate shaker for $30 \mathrm{~min}$. The neutral red fluorescence was then measured $\left(\lambda_{\text {ex }} 535 \mathrm{~nm}\right.$; $\lambda_{\text {em }} 600 \mathrm{~nm}$ ) in accordance with our validated protocol (Dutot et al., 2010; Rat et al., 1994).

Assessment of metabolic activity using the Alamar Blue ${ }^{\circledR}$ assay Alamar Blue is an oxidation-reduction (redox) indicator that changes color from blue to red and fluoresces when it is reduced by cellular metabolic activity. It provides a rapid and sensitive method to evaluate cell viability (O'Brien et al., 2000; Larson et al., 1997) and has been used to evaluate the relative ocular lens cytotoxicity of multipurpose contact lens solutions (Oriowo, 2006; Pham and Huff, 1999). Alamar Blue (Sigma-Aldrich, Saint-Quentin Fallavier, France at $0.1 \mathrm{mg} / \mathrm{ml}(20 \mu \mathrm{l})$ was diluted in culture medium supplemented with $2.5 \%$ fetal bovine serum (200 $\mu 1$ ). After removal of the products being tested, the cells then were incubated with Alamar Blue solution for $6 \mathrm{~h}$ at $37^{\circ} \mathrm{C}$ in a moist atmosphere with $5 \% \mathrm{CO}_{2}$. The fluorescence then was measured $\left(\lambda_{\mathrm{ex}}=535 \mathrm{~nm} ; \lambda_{\mathrm{em}}=600 \mathrm{~nm}\right)$ in accordance with our validated protocol (Dutot et al., 2008a; Perrot et al., 2003).

\section{Experimental procedures to study the efficacy of}

\section{a contact lens rinse step}

A lens case, used for storage of contact lenses, contains $5 \mathrm{ml}$ of lens care solution. Over 20 cycles of lens use, the lens will be exposed to a total of $100 \mathrm{ml}$ of lens care solution. To substitute for 20 cycles, $100 \mathrm{ml}$ was chosen. A soaking time of $96 \mathrm{~h}$ was chosen to reach a plateau level of total accumulation on the lens. After the soaking time of $96 \mathrm{~h}$ in lens care solution (Optifree, Alcon; Biotrue, Bausch-Lomb; and Renu, BauschLomb), the lens (Acuvue Advance, Johnson\&Johnson or Proclear, Cooper Vision) was either placed directly in the center of a monolayer of human corneal epithelial cells (HCE cell line) in culture medium (based on 1994 FDA Premarket Notification 510(k) Guidance Document for Daily Wear Contact Lens), or rinsed with $\mathrm{NaCl} 0.9 \%$ or controlled ionization marine solution-Lacrymer ${ }^{\circledR}$ (Yslab, Quimper, France) and exposed to these rinse solutions $(100 \mathrm{ml})$ for 24 hours. The cells were exposed to the lens for $24 \mathrm{~h}$ at $37^{\circ} \mathrm{C}$. Contact lenses directly removed from blisters were used as negative controls to assess the intrinsic cytotoxicity of contact lenses. Following exposure, the contact lens was taken out of the well and the cells were rinsed with phosphate buffer saline to remove detached cells. Extreme care was taken to minimize the movement of the lens during handling to avoid physical trauma to the cells. Then, a MTT test was performed to evaluate cell enzymatic activity.

\section{Assessment of mitochondrial succinate dehydrogenase activity using the MTT assay}

The assay is based on the reduction of the yellow tetrazolium salt MTT to water-insoluble purple formazan salt by viable cells. Cells were incubated with a MTT solution at $0.5 \mathrm{mg} / \mathrm{ml}$ for $3 \mathrm{~h}$ and rinsed with phosphate buffered saline. Formazan salt was solubilized in DMSO and absorbance detection $\left(\lambda_{\text {abs }}=\right.$ $540 \mathrm{~nm}$ ) was undertaken with a microplate colorimeter (Safire, Tecan, France).

\section{Statistical analysis}

Each concentration was tested in 6 wells and each test was performed independently in triplicate. Results were expressed 
Fig. 1: Evaluation of cell viability on WKD cell line after BAC incubation at different concentrations in two independent labs

(A) Neutral red uptake assay in lab 1,

(B) Neutral red uptake assay in lab 2,

(C) Alamar Blue assay in lab 1,

(D) Alamar Blue assay in lab 2. ***, $p<0.001$, **, $p<0.005$ and *, $p<0.01$ compared to negative control; $n=18$.

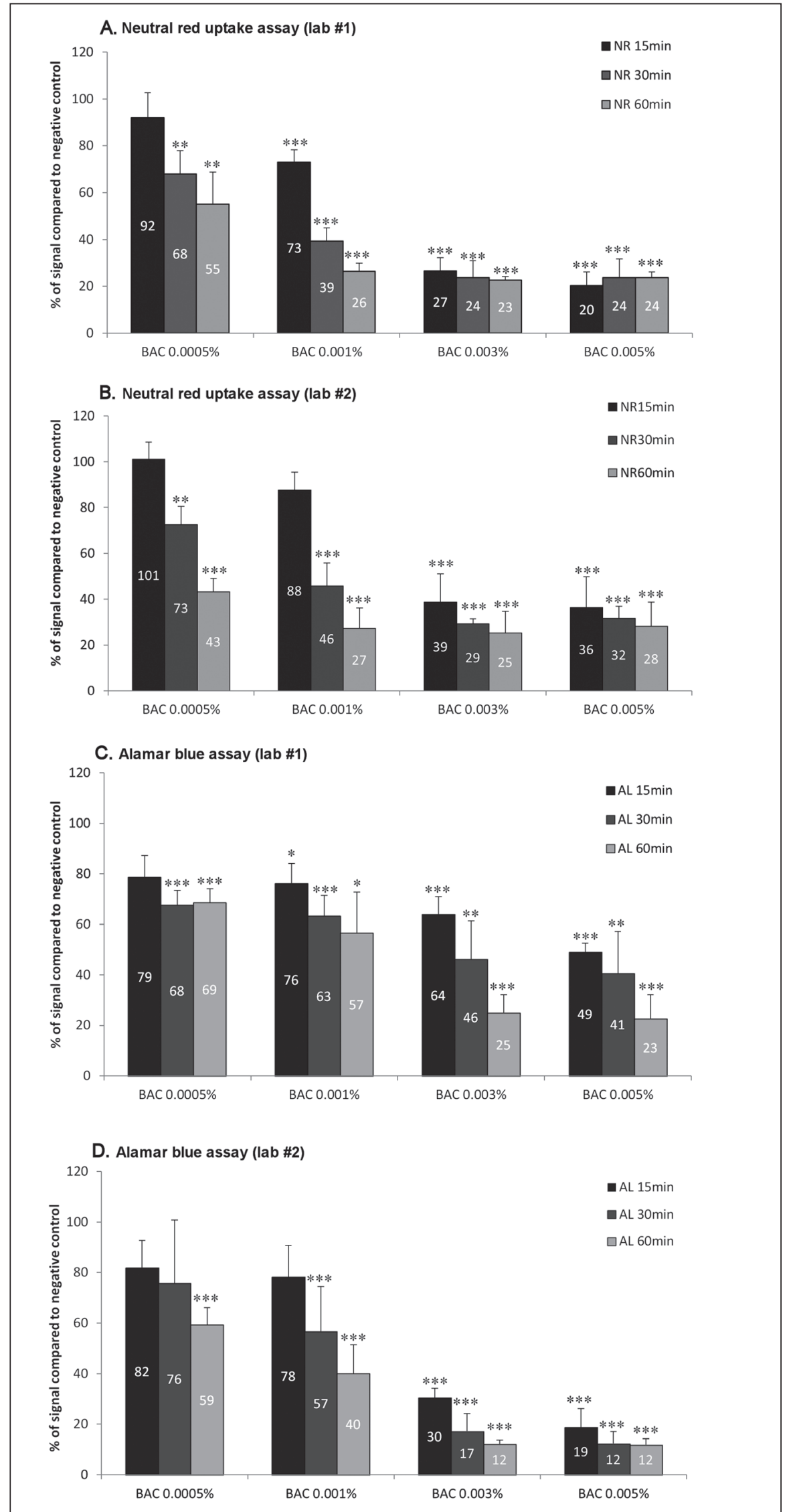


as a percentage of the control (cells in culture medium). The mean values were analyzed by one-way ANOVA followed by Dunnett's test. The level of significance was fixed at $0.05 \%$.

\section{Results}

Adjustment of concentration and incubation time for $B A C$ as positive control

Neutral red results with BAC in the two labs were very similar (Fig. 1A,B). Alamar blue results with BAC in the two labs also were very similar for the two lowest BAC concentrations but differed a little for the two highest BAC concentrations with higher levels of cytotoxicity found in lab 2 (Fig. 1C,D).

For the two lowest concentrations, BAC $0.0005 \%$ and BAC $0.001 \%$, the level of cytotoxicity depended on the incubation time. While the 15-minute incubation resulted in a low level of cytotoxicity of less than $30 \%$ for both concentrations detected in both assays, the 60-minute incubation resulted in up to $70 \%$ cytotoxicity in both neutral red and Alamar Blue assays. The higher concentrations of BAC, i.e., $0.003 \%$ and $0.005 \%$, both induced around $80 \%$ cytotoxicity after 15,30 , or 60 minutes.

\section{ISO 10993-5 standard adaptation to multipurpose solutions}

Solutions A and $\mathrm{F}$ were not significantly cytotoxic at any tested time 15, 30, or 60 minutes (Fig. 2).

Solution E was the only solution to cause a significant loss of cell viability after 15 minutes in both labs (37\% and $69 \%$ of control according to neutral red assay in lab 1 and lab 2, respectively; $57 \%$ and $66 \%$ according to Alamar Blue assay in lab 1 and lab 2, respectively).

As seen in Figure 2A and B, solutions B, C, D, and E induced a large decrease in neutral red signal in both labs after 30 minutes (between $17 \%$ and $59 \%$ of negative control in lab 1 and between $26 \%$ and $74 \%$ of negative control in lab 2) and after 60 minutes.

The neutral red test and the Alamar Blue test yielded similar results in both labs.

In ascending order of cytotoxicity, the ranking of the multipurpose solutions was as follows: $\mathrm{A}$ and $\mathrm{F}<\mathrm{C}<\mathrm{B}$ and $\mathrm{D}<\mathrm{E}$.

Efficacy of a contact lens rinse step with unpreserved solutions Incubation of corneal cells with Acuvue Advance and Proclear contact lenses removed from blisters induced a significant decrease in cell activity to $71 \%$ and $83 \%$ of negative control respectively (Fig. 3A,B). When either lens had been soaked in multipurpose solution E, cell enzymatic activity fell to 44 and $74 \%$ of negative control respectively, which was significantly less than contact lenses removed from blisters. When Proclear lens had been soaked in C, cell enzymatic activity fell significantly to $68 \%$. When either Proclear or Acuvue Advance were rinsed with $\mathrm{NaCl} 0.9 \%$ or controlled ionization marine solution $\left(\right.$ Lacrymer $\left.^{\circledR}\right)$, cell enzymatic activity significantly increased and was not different from negative control.

\section{Discussion}

In this study we performed a new protocol based on ISO 10993-5 standard in order to better evaluate ocular tolerance/ biohazard of lens care solutions. This new methodology has to fit the clinical use of these solutions better than the current ISO 10993-5 standard. The changes we propose to the ISO 109935 standard have been accepted by the French national organization for standardization (AFNOR) and are included in the NF S11-820 standard. Our study was conducted in two different laboratories.

ISO 10993-5 standard recommends the use of an established cell line for cytotoxicity studies and mentions the classical L929 cell line. L929 cells are fibroblasts of murine origin; as human epithelial cells are available in cell banks, we performed our studies on human ocular epithelial cells (WKD cell line, ATCC CCL-20.2), which have already been proposed for in vitro ocular toxicity studies (Brasnu et al., 2008). ISO 10993-5 standard recommends dilutions series to evaluate solutions' cytotoxicity and it recommends incubating the cells with solutions for a minimum of 24 hours. Physiologically, multipurpose solutions, as well as eye drops, are in direct contact with the ocular surface cells for a short incubation time; therefore, we evaluated the cytotoxicity of neat multipurpose solutions after three short incubation times: 15, 30, and 60 minutes.

Our first goal was to set up a positive control. BAC was chosen and different concentrations and incubation times were evaluated. The 30-minute incubation time was the best time for observing mild cytotoxicity (around 30\% and 60\%) with the lower concentrations BAC $0.0005 \%$ and $0.001 \%$. The two higher BAC concentrations $(0.003$ and $0.005 \%)$ are not suitable as positive cytotoxicity controls because the percentage of living cells is too low. The lowest concentration did not induce sufficient cell death after 30 minutes according to Alamar Blue results in lab 2; therefore, 30-minute incubation with $\mathrm{BAC} 0.001 \%$ appears to be the most relevant positive control for ocular cytotoxicity assays. Sodium laurylsulfate is proposed in ISO 10993-5 standard as positive control, but BAC $\mathrm{IC}_{50}$ is lower than sodium laurylsulfate $\mathrm{IC}_{50}(0.001 \%$ versus $0.0093 \%$; Spielmann et al., 1991), and BAC is already known to be toxic for the ocular surface (Debbasch et al., 2001; Grant et al., 1996; Green et al., 1987; Saarinen-Savolainen et al., 1998; Takahashi, 1982; Tripathi et al., 1992). Besides, unlike sodium laurylsulfate, BAC is a chemical found in ophthalmic solutions. For all these reasons, BAC should be preferred over sodium laurylsulfate as positive control for the evaluation of ocular cytotoxicity, and short incubation times (less than 1 hour) should be preferred.

Our second goal was to study multipurpose solutions' cytotoxicity based on the settings of the first step, i.e., after short incubation times. Multipurpose solutions can be released from contact lenses and may cause damage to the ocular surface during lens wear (Powell et al., 2010), so we chose to test neat multipurpose solutions to be closer to their use in practice. Using this approach it was possible to discriminate among multipurpose solutions; the ranking in term of cytotoxicity was the same in both labs. Here again, the 30-minute was found to be most suitable incubation 
Fig. 2: Evaluation of cell viability on WKD cell line after incubation with multipurpose solutions using neutral red uptake and Alamar Blue assays in two independent labs

(A) Neutral red uptake assay in lab 1,

(B) Neutral red uptake assay in lab 2,

(C) Alamar Blue assay in lab 1,

(D) Alamar Blue assay in lab 2.

***, $p<0.001,{ }^{* *}, p<0.005$ and ${ }^{*}, p<0.01$ compared to negative control; $n=18$.

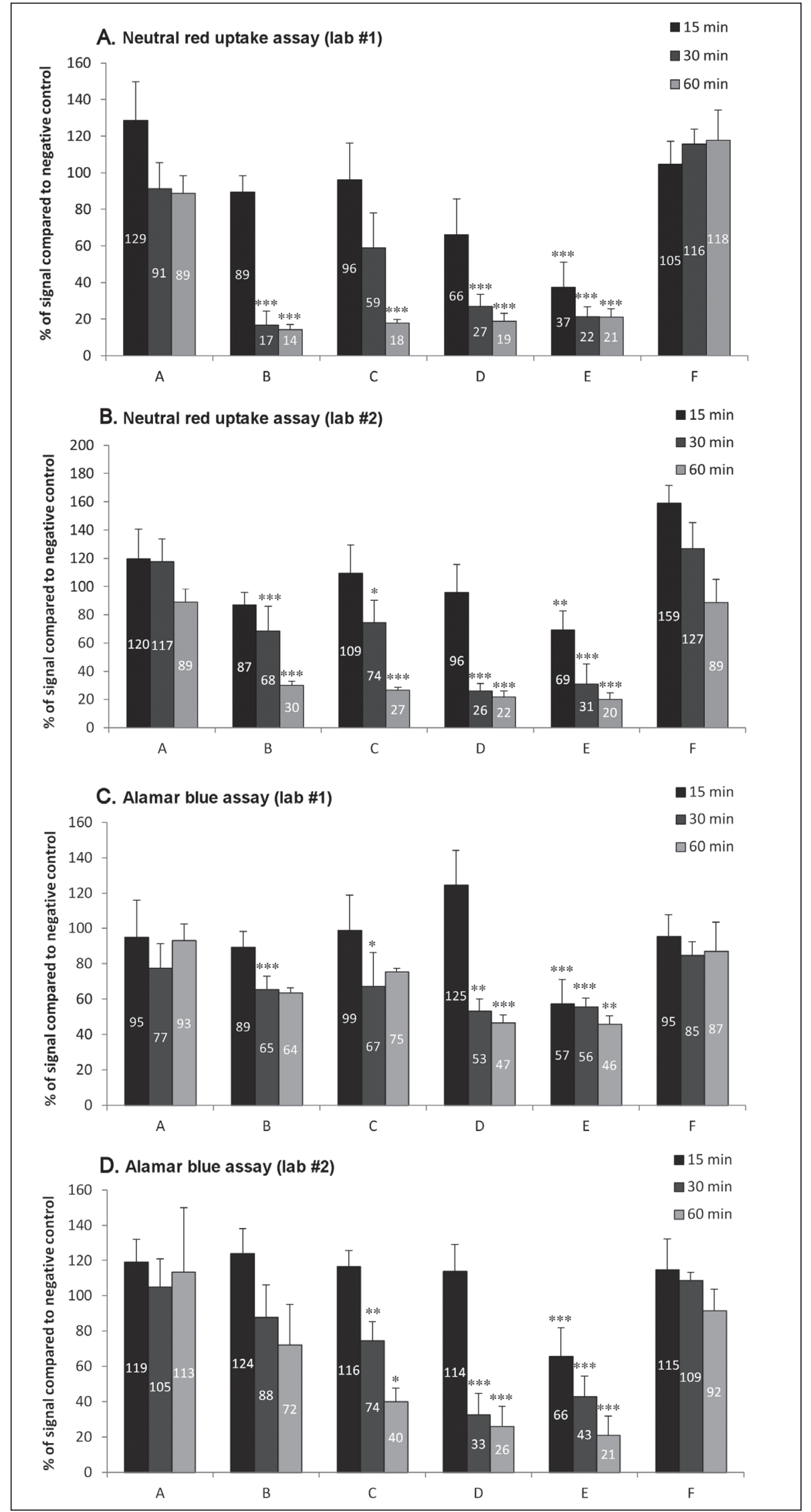


A

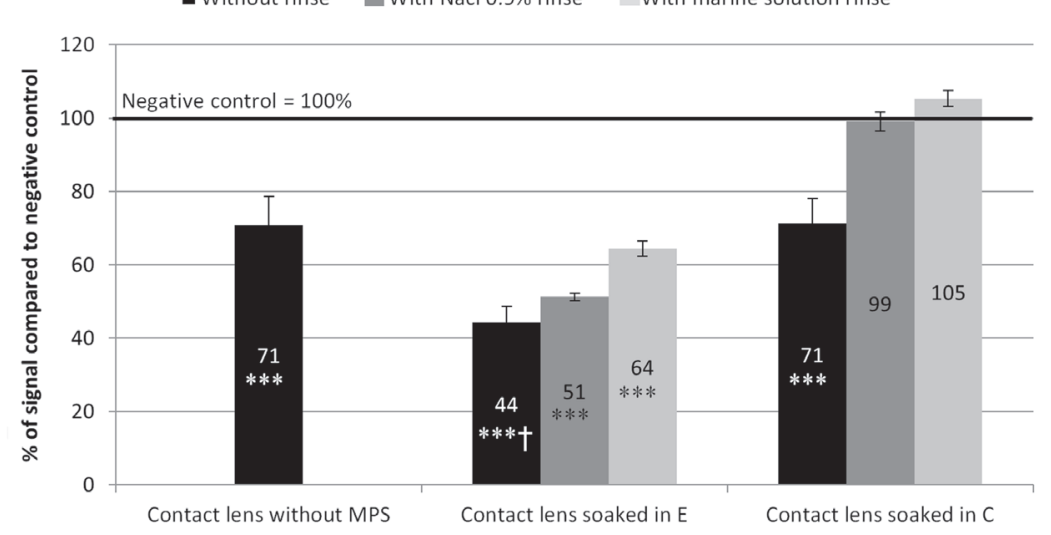

B

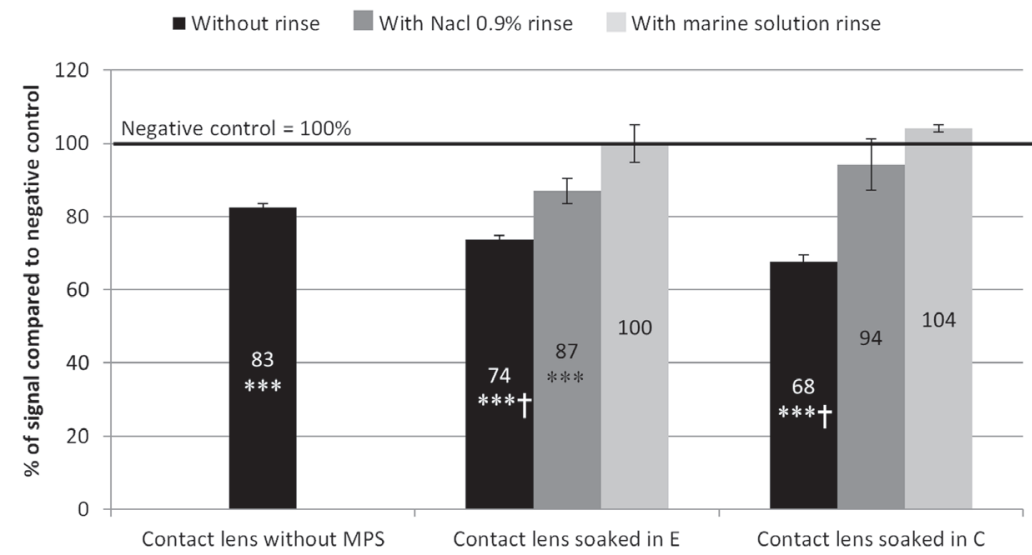

Fig. 3: Percentage of cell enzymatic activity after incubation of corneal cells with contact lens

A: Acuvue Advance lenses were soaked in multipurpose solutions $\mathrm{E}$ or $\mathrm{C}$ for $96 \mathrm{~h}$ and rinsed or not with $\mathrm{NaCl} 0.9 \%$ or marine solution for $24 \mathrm{~h}$. Corneal cells were then incubated with Acuvue Advance for $24 \mathrm{~h}$, B: Proclear lenses were soaked in multipurpose solutions $\mathrm{E}$ or $\mathrm{C}$ for $96 \mathrm{~h}$ and rinsed or not with $\mathrm{NaCl} 0.9 \%$ or marine solution for $24 \mathrm{~h}$. Corneal cells were incubated with Proclear for $24 \mathrm{~h}$. ${ }^{* \star *}, \mathrm{p}<0.001$ compared to negative control; $\uparrow, p<0.001$ compared to contact lens without multipurpose solution (MPS). $n=6$

time to discriminate multipurpose solutions. In ascending order of cytotoxicity, the ranking of the multipurpose solutions is: A and $\mathrm{F}$ (no cytotoxicity) $<\mathrm{C}<\mathrm{B}$ and $\mathrm{D}<\mathrm{E}$. This classification is in accordance with their formulation (see Tab. 1): Solution E, the only solution to contain quaternary ammonium, is the most cytotoxic solution; solutions A and F have the same manufacturer and seem to be the only safe solutions. Solution A was the multipurpose solution with the lowest PHMB concentration at the time of the study; that could explain the absence of adverse cellular effects. PHMB is present at the same concentration in solutions $\mathrm{F}$ and $\mathrm{D}$, the latter being among the most cytotoxic solutions. Solution F also contains hydroxypropyl methylcellulose that could protect cells from PHMB cytotoxicity. Indeed, hydrogels already have been identified as ocular cytoprotective agents (Debbasch et al., 2002; Pauloin et al., 2008, 2009). Besides, preservatives do not have sole responsibility for multipurpose solutions' cytotoxicity; excipients also can play a role. Attention should be paid to the formulation of these ophthalmic solutions because the concentration of active principle (mostly PHMB) often is modified by the manufacturer (for example PHMB in Boston Simplus was $0.0005 \%$ in 2011).

Solution E was the most cytotoxic multipurpose solution and the only one to contain quaternary ammonium (Polyquad ${ }^{\circledR}$ ) as active principle. Yet this solution is among the best-selling multipurpose solutions in Europe and America. Our results indicate that both silicone and silicone hydrogel lenses released solution E on corneal cells, thus increasing contact lens cytotoxicity. Corneal cells were used because contact lenses are put directly on the cornea in clinical practice. The cytotoxic effects induced by the contact lenses alone ( $71 \%$ of cell enzymatic activity after incubation of corneal cells with Acuvue Advance and $83 \%$ of cell enzymatic activity after Proclear) are 
significantly inferior to the cytotoxic effects induced by the multipurpose solutions alone. Consequently, the risk of contact lens intolerance among multipurpose solutions users may be due to the multipurpose solution more than to the lens material. A rinse step with unpreserved solutions ( $\mathrm{NaCl} 0.9 \%$ or controlled ionization marine solution) induced a considerable gain in cell enzymatic activity.

Solution C differs from the other multipurpose solutions by the presence of an oxidant agent (oxychlorite) instead of a preservative. As it induced cell death as soon as 30 minutes, we also evaluated the benefits of a rinse step after use of this solution and observed that unpreserved saline solutions again avoided cytotoxicity. In each case, the controlled ionization controlled marine solution was more efficient than $\mathrm{NaCl} 0.9 \%$ to rinse contact lenses, which is in accordance with previous results (Dutot et al., 2010; Said et al., 2009). Oligoelements and ions are already known to exert beneficial ocular effects (Dutot et al., 2008b).

\section{Conclusion}

Concerning the adaptation of ISO 10993-5 standard to multipurpose solutions, data obtained were similar in both laboratories. Globally, even if less cytotoxicity is observed with the Alamar Blue protocol, results are equivalent to neutral red results. Therefore, both neutral red and Alamar Blue assays can be used for the evaluation of ocular medical devices. ISO 10993-5 standard has to be adapted to ocular devices: to run a discriminant analysis of ocular cytotoxicity, ophthalmic solutions such as multipurpose solutions should be evaluated neat and after a 30-minute incubation time on human ocular epithelial cells, using BAC $0.001 \%$ as positive control. This protocol, the first step of global risk analysis, provided a fast, cheap, and reproducible methodology, and it should be included in screening tests to define lens care solutions' biocompatibility. In addition, marketed multipurpose solutions that represent a risk for patients should be rinsed off contact lenses with unpreserved solutions after use.

\section{References}

Begley, C. G., Waggoner, P. J., Jani, N. B., and Meetz, R. E. (1994). The effects of soft contact lens disinfection solutions on rabbit corneal epithelium. CLAO J 20, 52-58.

Bourcier, T., Thomas, F., Borderie, V., et al. (2003). Bacterial keratitis: predisposing factors, clinical and microbiological review of 330 cases. Br J Ophthalmol 87, 834-838.

Brasnu, E., Brignole-Baudouin, F., Riancho, L., et al. (2008). Comparative study on the cytotoxic effects of benzalkonium chloride on the Wong-Kilbourne derivative of Chang conjunctival and IOBA-NHC cell lines. Invest Ophtalmol Vis Sci 40, 619-630.

Burstein, N. L. (1980). Preservative cytotoxic threshold for benzalkonium chloride and chlorhexidine diclugonat in rat and rabbit cornea. Invest Ophtalmol Vis Sci 47, 4221-4230.
Burstein, N. L. (1985). The effects of topical drugs and preservatives on the tears and corneal epithelium in dry eye. Ophtalmol Soc UK 104, 402-409.

Champeau, E. J. and Edellhauser, H. F. (1998). Effects of ophthalmic preservatives on the ocular surface: conjunctival and corneal uptake and distribution of benzalkonium chloride and chlorhexidine digluconate. In F. Holly, D. Lamberts, and D. Mac Keen (ed.), The preocular tear film in health, disease, and contact lens wear (292-302). Lubbock: Dry Eye Institute, Inc..

Chang, J. H., Ren, H. W., Petroll, M. W., et al. (1999). The application of in vivoconfocal microscopy and tear LDH measurement in assessing corneal response to contact lens and contact lens solutions. Curr Eye Res 19, 171-181.

Claydon, B. and Efron, N. (1994). Non-compliance in contact lens wear. Ophthal Physiol Opt 14, 356-364.

Debbasch, C., Rat, P., Warnet, J. M., et al. (2000). Evaluation of the toxicity of benzalkonium chloride on the ocular surface. $J$ Toxicol Cutaneous Ocul Toxicol 19, 105-115.

Debbasch, C., Brignole, F., Pisella, P. J., et al. (2001). Quaternary ammoniums and other preservatives. Contribution in oxidative stress and apoptosis on Chang Conjunctival Cells. Invest Ophtalmol Vis Sci 42, 642-652.

Debbasch, C., De La Salle, S. B., Brignole, F., et al. (2002). Cytoprotective effects of hyaluronic acid and Carbomer 934P in ocular surface epithelial cells. Invest Ophthalmol Vis Sci 43, 3409-3415.

De Saint Jean, M., Brignole, F., Bringuier, A. F., et al. (1999). Effects of Benzalkonium Chloride on growth and survival of Chang conjunctival cells. Invest Ophtalmol Vis Sci 40, 619-630.

Dutot, M., Pouzaud, F., Larosche, I., et al. (2006). Fluoroquinolone eye drop-induced cytotoxicity: role of preservative in $\mathrm{P} 2 \mathrm{X} 7$ cell death receptor activation and apoptosis. Invest Ophtalmol Vis Sci 47, 2812-2819.

Dutot, M., Warnet, J. M., Baudouin, C., and Rat, P. (2008a). Cytotoxicity of contact lens multipurpose solutions: Role of oxidative stress, mitochondrial activity and P2X7 cell death receptor activation. Eur J Pharm Sci 33, 138-145.

Dutot, M., Liang, H., Pauloin, T., et al. (2008b). Effects of toxic cellular stresses and divalent cations on the human P2X7 cell death receptor. Mol Vis 14, 889-897.

Dutot, M., Reveneau, E., Pauloin, T., et al. (2010). Multipurpose solutions and contact lens: modulation of cytotoxicity and apoptosis on the ocular surface. Cornea 29, 541-549.

Geerling, G., Daniels, J., Dart, J. K. D., et al. (2001). Toxicity of natural tear substitutes in a fully definedculture model of human corneal epithelial cells. Invest Ophtalmol Vis Sci 42, 948-956.

Gower, L., Stein, J., and Turner, F. (1994). Compliance: a comparison of three lens care systems. Optom Vis Sci 71, 629-643.

Grant, R. L., Acosta, D., and Gregerson, D. (1996). Prolonged adverse effects of benzalkonium chloride and sodium dodecyl sulphate in a primary culture system of rabbit corneal epithelial cells. Fundam Appl Toxicol 33, 71-82.

Green, K., Chapman, J. M., Cheeks, L., et al. (1987). Detergent penetration into young and adult rabbit eyes: comparative 
pharmacokinetics. J Toxicol Cut Ocul Toxicol 6, 89-107.

Ladage, P. M., Yamamoto, K., Ren, D. H., et al. (2001). Effects of rigid and soft contact lens daily wear on corneal epithelium, tear lactate dehydrogenase, and bacterial binding to exfoliated epithelial cells. Ophthalmology 108, 1279-1288.

Larson, E. M., Doughman, D. J., Gregerson, D. S., and Obritsch, W. F. (1997). A new, simple, nonradioactive, non-toxic in vitro assay to monitor corneal endothelial cell viability. Invest Ophtalmol Vis Sci 38, 1929-1933.

Lebow, K. A. and Schachet, J. L. (2003). Evaluation of corneal staining and patient preference with the use of three multipurpose solutions and two brands of soft contact lenses. Eye Contact Lens 29, 213-220.

Li, S. L., Ladage, P. M., Yamamoto, T., et al. (2003). Effects of contact lens care solutions on surface exfoliation and bacterial binding to corneal epithelial cells. Eye Contact Lens 29, 27-30.

Mowrey-McKee, M., Sills, A., and Wright, A. (2002). Comparative cytotoxicity potential of soft contact lens care regimens. CLAO J 28, 160-164.

O'Brien, J., Wilson, I., Orton, T., and Pognan, F. (2000). Investigation of the Alamar Blue (resazurin) fluorescent dye for the assessment of mammalian cell cytotoxicity. Eur J Biochem 267, 5421-5426.

Oriowo, M. O. (2006). A fluorometric study of ocular lens cytosensitivity to multipurpose contact lens solutions using the resazurin assay method. Toxicol In Vitro 20, 1548-1554.

Pauloin, T., Dutot, M., Warnet, J. M., and Rat, P. (2008). In vitro modulation of preservative toxicity: high molecular weight hyaluronan decreases apoptosis and oxidative stress induced by benzalkonium chloride. Eur J Pharm Sci 34, 263-273.

Pauloin, T., Dutot, M., Liang, H., et al. (2009). Corneal protection with high-molecular-weight hyaluronan against in vitro and in vivo sodium lauryl sulfate-induced toxic effects. Cornea 28, 1032-1041.

Pauly, A., Meloni, M., Brignole-Baudouin, F., et al. (2009). Multiple endpoint analysis of the 3D-reconstituted corneal epithelium (SkinEthic ${ }^{\mathrm{TM}}$ ) after treatment with benzalkonium chloride: modified MTT procedure and new markers for the early detection of toxic damage. Invest Ophtalmol Vis Sci 47 , 2812-2819.

Perrot, S., Dutertre-Catella, H., Martin, C., et al. (2003). Resazurin metabolism assay is a new sensitive alternative test in isolated pig cornea. Toxicol Sci 72, 122-129.

Pham, X. T. and Huff, J. W. (1999). Cytotoxicity evaluation of multipurpose contact lens solutions using an in vitro test battery. CLAO J 25, 28-35.

Powell, C. H., Lally, J. M., Hoong, L. D., and Huth, S. W. (2010). Lipophilic versus hydrodynamic modes of uptake and release by contact lenses of active entities used in multipurpose solutions. Cont Lens Anterior Eye 33, 9-18.

Rat, P., Korwin-Zmijowska, C., Warnet, J. M., and Adolphe, M. (1994). New in vitro fluorimetric microtitration assays for toxicological screening of drugs. Cell Biol Toxicol 10, 329-337.

Saarinen-Savolainen, P., Järvinen, T., Araki-Sasaki, K., et al. (1998). Evaluation of cytotoxicity of various ophthalmic drugs, eye-drop excipients and cyclodextrins in an immortalized human corneal epithelial cell line. Pharm Res 15, 1275-1280.

Said, T., Dutot, M., Labbé, A., et al. (2009). Ocular burn: rinsing and healing with ionic marine solutions and vegetable oils. Ophthalmologica 223, 52-59.

Santodomingo-Rubido, J., Mori, O., and Kawaminami, S. (2006). Cytotoxicity and antimicrobial activity of six multipurpose soft contact lens disinfecting solutions. Ophtalm Physiol Opt 26, 476-482.

Spielmann, H., Gerner, I., Kalweit, S., et al. (1991). Interlaboratory assessment of alternatives to the Draize eye irritation test in Germany. Toxicol In Vitro 5, 539-542.

Takahashi, N. (1982). Quantitative cytotoxicity of preservatives evaluated in cell culture with Chang's human conjunctival cells-effect of temperature on cytotoxicity. Jpn J Ophthalmol 26, 234-238.

Tchao, R., McCanna, D. J., and Miller, M. J. (2002). Comparison of contact lens multipurpose solutions by in vitro sodium fluoresceine permeability assay. CLAO J 28, 151-156.

Tripathi, B. J., Tripathi, R. C., and Kolli, S. P. (1992). Cytotoxicity of ophthalmic preservatives on human corneal epithelium. Lens Eye Toxicol Res 9, 361-375.

Wright, A. and Mowrey-McKee, M. (2005). Comparative cytotoxicity potential of soft contact lens care products. Cutan Ocul Toxicol 24, 53-64.

\section{Acknowledgements}

The authors from Université Paris Descartes would like to thank Adebiopharm ER67 for their financial support.

\section{Correspondence to}

Patrice Rat, $\mathrm{PhD}$

Laboratoire de Chimie-Toxicologie Analytique et Cellulaire

Faculté de Pharmacie, Université Paris Descartes

4 avenue de l'Observatoire

75006 ParisFrance

Phone: +33153739861

Fax: +33143267122

e-mail: patrice.rat@parisdescartes.fr 